\title{
Análisis del marco legal para la implementación y desarrollo del proceso de paz con los grupos paramilitares
}

\author{
Analysis of the legal framework for the implementation and \\ development of the peace process with paramilitary groups
}

\begin{abstract}
Nydian Yaneth Contreras Rodríguez
Abogada por la Universidad Santo Tomás Bucaramanga (Col.); doctorado (en curso) por la Universidad de Granada, España; miembro investigador del Instituto de la Paz y los Conflictos de la Universidad de Granada.

Correo electrónico: nidiancontreras@gmail.com
\end{abstract}

\section{Jaime Andreu Abela}

Licenciado en Sociología y Comunicación Audiovisual, máster universitario en Problemas Sociales, Dirección y Gestión de Programas Sociales; profesor titular de la Universidad de Granada.

Correo electrónico: jandreu@ugr.es

\begin{abstract}
Resumen
Colombia enfrentó durante la primera década del siglo XXI un proceso de paz dentro del marco legal de la que se denominó Ley de Justicia y Paz, aprobada por el Congreso en el 2005, siendo sus principales protagonistas los grupos armados conocidos como Paramilitares. Este proceso tuvo gran relevancia para la vida social, política y económica del país. La Ley de Justicia y Paz conduciría al desarme e incorporación a la vida civil de más de 30000 excombatientes, asimismo, a la reparación integral de las víctimas del conflicto a través de los mecanismos incorporados para tales efectos dentro de la Ley. Con este estudio, pretendemos hacer un análisis jurídico de la base e instrumentos legales establecidos para el cumplimiento de los objetivos del proceso, los obstáculos a los que se ha tenido que enfrentar, las reformas y las críticas de las que ha sido objeto. De otro lado, se quiere resaltar la importancia de la Justicia Transicional dentro de un proceso de paz, exponiendo de manera general sus elementos y fines principales.
\end{abstract}

Palabras clave: Ley de Justicia y Paz, paramilitarismo, derechos de las víctimas, justicia transicional, desmovilización.

Abstract

During the first decade of the 21st century, Colombia began a peace process, which was passed by Congress in 2005, called "Justice and Peace Law". This law was aimed at armed groups outside the law known as Paramilitaries. This process was highly relevant to the social, political and economic life of the country. The "Justice and Peace Law" which led to disarmament and the integration into civilian life of more than 30,000 former combatants. With this study, we intend to make a legal analysis of the base and fulfill the objectives of the legal process, the obstacles they have faced, reforms as well as criticism than it has faced. We also want to highlight the importance of Transitional Justice in a peace process, which exposes its main objectives.

Keywords: Justice and Peace Law, paramilitarism, victims' rights, transitional justice, demobilization.

Recibido: 17 de septiembre de 2015; Aprobado: 10 de noviembre de 2015 


\section{Résumé}

La Colombie fait face au cours de la première décennie du siècle, un processus de paix dans le cadre juridique qui «Loi pour la justice et la paix», adoptée par le Congrès en 2005 a été appelé, et ses principaux protagonistes des groupes connus comme des paramilitaires armés. Ce processus a eu une grande importance pour la vie sociale, politique et économique du pays. La «Loi de Justice et Paix» conduire au désarmement et à l'intégration dans la vie civile de plus de 30.000 anciens combattants aussi à une pleine indemnisation des victimes du conflit à travers les mécanismes intégrés à cet effet dans la loi. Cette étude, nous avons l'intention de faire une analyse juridique de la base et mis en place pour atteindre les objectifs des instruments juridiques de processus, les obstacles qui ont été rencontrés, les réformes et la critique qu'elle ne l'a été. D'autre part, nous voulons souligner l'importance de la justice transitionnelle dans un processus de paix, exposant généralement tous ses éléments et objectifs principaux.

Mots-clés: Loi de Justice et Paix, le paramilitarisme, les droits des victimes, la justice transitionnelle, la démobilisation. 


\section{Análisis del marco legal para la implementación y desarrollo del proceso de paz con los grupos paramilitares}

Nydian Yaneth Contreras Rodriguez

Jaime Andreu Abela

\section{INTRODUCCIÓN}

Los conflictos armados de larga duración contra grupos insurgentes han favorecido, históricamente, la aparición de grupos paramilitares de autodefensas. La constante inseguridad y la sensación de vulnerabilidad de los habitantes llevaron a que diversas facciones se armaran bajo la premisa de proteger a sus comunidades de los continuos ataques por parte de las guerrillas. En el caso colombiano la situación no fue diferente, y es así como desde finales de la década de los ochenta comenzaron a visibilizarse actuaciones de los grupos de autodefensa en el territorio nacional. Grupos amparados por la fuerza pública y por el Decreto Legislativo 3398 de $1965^{1}$, por el cual se organiza la defensa nacional y permite al Estado armar a la población civil para hacer frente a los grupos insurgentes, que fue adoptado como legislación permanente mediante la Ley 48 de 1968.

Si bien dicha Ley sería eliminada unos años después durante el mandato del presidente Ernesto Samper, siguiendo así una política establecida por su predecesor César Gaviria (Comisión Interamericana de Derechos Humanos, 1999), más tarde se daría lugar a la creación de las Cooperativas de Vigilancia - Convivir, que revivirían la figura de los grupos civiles armados de autodefensa.

1 Este Decreto adoptado bajo el gobierno de Guillermo León Valencia, legalizó las autodefensas, equiparando el deber de defensa de las Fuerzas Armadas, con el que debía tener la población civil. 
Posteriormente, y con la desaparición de las Convivir ${ }^{2}$ en 1997, empezaría lo que algunos analistas han llamado "la verdadera paramilitarización del conflicto colombiano" (Restrepo, Spagat y Vargas, 2004), con la entrada en escena, de forma directa, de las Autodefensas Unidas de Colombia - AUC. Una organización ilegal que, bajo el argumento de combatir a la guerrilla, congregó a diversos grupos paramilitares del país como las Autodefensas Unidas del Magdalena y las Autodefensas Campesinas de Córdoba y Urabá, y así coordinar sus esfuerzos y lograr el control de buena parte del territorio nacional.

Esta organización ilegal, con el pretexto del cumplimiento de sus fines de lucha contra la insurgencia, inició una dura y cruenta ofensiva armada contra los grupos insurgentes y contra todos aquellos que consideraban sus colaboradores. Por esto último, sus ataques también tuvieron como blanco recurrente a la población civil, realizando masacres contra campesinos y pobladores, acusados de ayudar a la guerrilla. Todo esto llevó a que la Unión Europea (El Mundo, 2002) y los Estados Unidos de Norteamérica (Department of State, 2001) declararan a las AUC como grupo terrorista, amenazando al país con sanciones si no tomaba acciones directas contra dicho grupo. De igual forma, diversos sectores acusaron al Gobierno colombiano y a sus Fuerzas Militares de apoyar a las AUC, con la intención de debilitar a los grupos guerrilleros (Velázquez, 2007).

En 2006 el grueso de las AUC se desmovilizó durante el gobierno de Álvaro Uribe Vélez, y muchos de sus principales líderes fueron extraditados a Estados Unidos. Dicho proceso de desmovilización, si bien disminuyó ampliamente la violencia paramilitar no la eliminó por completo, y nuevas organizaciones como "Las Águilas Negras" y muchas de las actuales Bandas Criminales ${ }^{3}$ (Bacrim) intentan recuperar el control de las zonas que eran gobernadas por los paramilitares, considerándose herederas directas de las AUC.

El largo, intenso y violento conflicto interno que han vivido los colombianos durante más de seis décadas ha dejado, en su desarrollo, un enorme número de víctimas cuya totalidad resulta difícil de medir. Se habla de una cifra aproximada de $220000^{4}$ muertos desde 1958 hasta 2012, de los cuales 176000 eran víctimas civiles. Si a este número se le suman las víctimas supervivientes, es decir, los desplazados, los menores reclutados de forma forzosa y otras personas afectadas de forma indirecta por el conflicto, la cifra se acerca a un total de 6 millones.

2 Cooperativas de Vigilancia y Seguridad Privada para la autodefensa agraria, reglamentadas bajo el gobierno de Ernesto Samper, dotaban de competencia legal a los dueños de las tierras para defenderse de los grupos guerrilleros.

3 Organizaciones criminales que emergieron después de la desmovilización de los grupos de autodefensa, actúan actualmente en todo el territorio nacional, se consolidaron como una especie de reestructuración del crimen organizado.

4 Cifras desde el 1 de enero 1958 hasta el 31 de diciembre de 2012, según datos del Centro Nacional de Memoria Histórica (2013). Información disponible en: http://www.centrodememoriahistorica. gov.co/micrositios/informeGeneral/estadisticas.html 
A pesar de este número, durante la mayor parte del conflicto las víctimas han sido casi invisibles. Centrados en los combatientes, la mayoría de los informes presentados sobre el conflicto durante sus primeras cinco décadas, hablaban solo de bajas y combates, enfrentamientos y éxitos militares, dejando a las víctimas en un plano remoto, ignoradas casi por completo. No fue hasta una década después, de la entrada en vigencia de la Constitución Política de 1991, cuando las víctimas del conflicto empezaron a tomar notoriedad, especialmente a partir de los fallos de la Corte Constitucional Colombiana, donde se resaltaba el daño que habían recibido los civiles, tanto por parte de los grupos alzados en armas como por parte de las fuerzas del Estado y de los grupos paramilitares, al tiempo en que se recordaba la responsabilidad del Estado para con dichos afectados.

La entrada en escena de las víctimas se vio reforzada con la entrada en vigencia de la Ley de Justicia y Paz en el 2005 (Ley 975/05), instrumento jurídico mediante el cual se procedió a la desmovilización ${ }^{5}$ de diversos grupos paramilitares. Durante las fases de debate y aprobación de dicha Ley, el tema de las víctimas del paramilitarismo fue el más recurrente, especialmente a partir de la presión externa, ya que muchos entes de fuera del Estado, como los representantes de las víctimas, veían la norma como una herramienta generadora de impunidad.

De esta forma, en el contenido de la Ley de Justicia y Paz quedó consagrado como elemento central de la Justicia Transicional, el derecho que tienen las víctimas a la verdad, la justicia y la reparación. Así que, para que la desmovilización de los grupos armados al margen de la ley tuviera validez, era necesario que se respetaran los derechos de las víctimas a conocer la verdad de lo sucedido, a que se hiciera justicia sobre los delitos cometidos por las partes del conflicto que deponían las armas y a que estas repararan a las víctimas de sus actos. Aspectos que fueron resaltados, de igual forma, por la Corte Constitucional Colombiana en sus sentencias C-370 de 2006 y T-496 de 2008, recordando que de su cumplimiento dependía la validez de toda la norma.

Sin embargo, y a pesar de la inclusión de las víctimas en el contenido normativo y en las sentencias que respecto de este emitió la Corte Constitucional, muchos sectores han tildado a la Ley de Justicia y Paz como un fracaso legislativo y señalan que fueron muy pocas las víctimas que realmente fueron reparadas por los paramilitares desmovilizados, al igual que tampoco existió claridad sobre los delitos cometidos por los desmovilizados. De tal forma que no se vieron materializados los mencionados postulados de Verdad, Justicia y Reparación a los cuales tenían derecho las víctimas.

Este artículo tiene por finalidad hacer un estudio del marco jurídico que sirvió de base a la estructuración de los principales objetivos propuestos para adelantar el proceso de paz con los grupos paramilitares, además de realizar una revisión

$5 \quad$ El artículo $9^{\circ}$ de la Ley 975/05 ha definido la desmovilización como el acto individual o colectivo de dejar las armas y abandonar el grupo armado organizado al margen de la ley, realizado ante autoridad competente. 
jurisprudencial sobre las demandas de inconstitucionalidad más relevantes de las que ha sido objeto la Ley de Justicia y Paz.

Habiendo hecho el acercamiento al problema debemos preguntarnos: ¿los objetivos propuestos por la Ley de Justicia y Paz fueron lo suficientemente concretos y viables a la hora de llevarlos a cabo?, ¿constituyó la Ley 975/05 la herramienta idónea para la reparación eficaz de las víctimas?, ¿tuvo en cuenta la Ley las limitaciones del aparato estatal a la hora de establecer sus propósitos? Estas son algunas de las cuestiones que ocuparán la atención en el presente proyecto de investigación, cuestiones a las que pretendemos dar respuesta a través del estudio teórico y revisión del marco legal que dio paso a la promulgación de la Ley de Justicia y Paz, donde se analizarán y abordarán las siguientes leyes y decretos; Ley 782 de 2002 y Decreto 1000 de 2003, Decreto 128 de 2003, Decreto 2767 de 2004 y, finalmente, la Ley 795 de 2005: Ley de Justicia y Paz, de otro lado se hará una revisión documental y análisis de algunas de las sentencias que la Corte Constitucional ha proferido con motivo de las demandas de inconstitucionalidad más destacadas presentadas en contra de la Ley, entre ellas, la Sentencia C-928 de 2005, Sentencia C-370 de 2006 en la que se tratan diferentes problemas jurídicos, Sentencia C-575 de 2006 y por último la Sentencia C-1199 de 2008.

\section{MARCO JURÍDICO HACIA UNA SOLUCIÓN PACÍFICA}

Para entender el proceso que llevó a la desmovilización de los grupos paramilitares, resulta indispensable hacer un estudio y revisión del conjunto normativo que habilitó y desarrolló dicho proceso de diálogo y armisticio. Leyes, decretos, sentencias de la Corte Constitucional que dieron sustento legal a la desmovilización.

\section{A. Análisis de leyes y decretos}

\section{Ley 782 de 2002 y Decreto 1000 de 2003}

El primer acto legislativo emitido dentro del proceso de diálogo con las AUC fue la Ley 782 de 2002. Acto Legislativo destinado a modificar y mantener en vigencia la Ley 418 de 1997, que versaba sobre el desarme y reincorporación de grupos armados, con el fin de "facilitar el diálogo y la suscripción de acuerdos con grupos armados organizados al margen de la ley para su desmovilización, reconciliación entre los colombianos y la convivencia pacífica”. Esta Ley, a su vez, fue modificada poco después con el Decreto 1000 de 2003, que corrigió y complementó la redacción de algunos artículos de la norma para hacer mayor claridad sobre su contenido y finalidad. En conjunto, el dueto formado por la Ley 782 de 2002 y el Decreto 1000 de 2003 estableció una serie de herramientas para permitir y facilitar el diálogo.

1) El artículo 3 de la Ley 782 de 2002 otorgó al Estado la capacidad para designar un grupo de negociadores que tendría potestades no solo de llevar a 
cabo el diálogo, sino de buscarlo. Es decir, se le concedió a los negociadores elegidos por el gobierno la facultad de realizar actos previos de acercamiento con los grupos al margen de la ley, con el fin de fomentar el inicio de las conversaciones. No se necesitaba, de esta forma, que las condiciones de diálogo o acercamiento estuvieran dadas, ni que existiera voluntad previa por parte de los grupos armados al margen de la ley. Simplemente el gobierno podía crear al grupo de negociación de forma previa, para que este fuera quien intentara establecer un clima positivo para iniciar el proceso de diálogo.

2) De igual forma, y en el mismo artículo, se ampliaron las capacidades de dicho grupo negociador al permitirles realizar acuerdos previos con los grupos armados en nombre del gobierno. Si bien dichos acuerdos debían estar orientados a la finalización del conflicto o a su atenuación, también se debía garantizar el normal funcionamiento de las instituciones estatales en las áreas afectadas. El texto resulta bastante flexible en el contenido de los mismos, ya que dice que "los acuerdos y su contenido serán los que a juicio del Gobierno sean necesarios para adelantar el proceso de paz", permitiendo de esta forma un muy amplio campo de maniobra para los negociadores.

3) El primer parágrafo del artículo tercero introduce en el texto, al hablar de grupos armados al margen de la ley, una definición proveniente del Derecho Internacional Humanitario ${ }^{6}$ según la cual se considera a todo aquel grupo que "bajo la dirección de un mando responsable, ejerza sobre una parte del territorio un control tal que le permita realizar operaciones militares sostenidas y concertadas". Esto permitió, de forma clara, introducir bajo dicha definición -que carece por sí misma de connotaciones políticas- no solo a los grupos guerrilleros, sino también a los grupos paramilitares que controlaban en ese momento amplias regiones del territorio nacional.

Esto fue motivo de disputa ya que se decía que de esta forma se concedía de manera tácita a los paramilitares el estatus de delincuentes políticos, que pertenecía por definición a los grupos insurgentes, permitiendo procesos de indulto y amnistía ${ }^{7}$ hacía los mismos (Colectivo de Abogados José Alvear Restrepo, 2006). Los detractores consideraban que por la naturaleza de sus crímenes, y por sus graves ataques contra la población civil, no se debía ni podía dar estatus político a los grupos paramilitares.

6 Se encuentra formado por el conjunto de normas que, por razones humanitarias, trata de poner un límite a los efectos causados por los conflictos armados y de proteger a las personas que no participan o que han dejado de participar en los combates, además limita los medios y métodos de hacer la guerra. Suele denominarse también "derecho de la guerra" y "derecho de los conflictos armados".

7 Constituyen dos tipos de beneficios, el indulto pone fin a la responsabilidad penal, es decir, supone el perdón de la pena. Mientras que la amnistía es una causa del fin de la responsabilidad otorgada por el poder legislativo. 
4) A su vez, el segundo parágrafo del artículo tercero permite al Gobierno solicitar a la rama judicial la suspensión temporal de las órdenes de captura que pesen sobre los miembros de los grupos al margen de la ley que fueran designados como voceros y representantes. Esto permitió que los miembros de mayor importancia, o representatividad dentro de la jerarquía de dichos grupos, pudieran tomar parte en las negociaciones sin necesidad de recurrir a intermediarios o representantes sobre los cuales no pesaran órdenes de captura vigentes, lo cual haría más lentas y complicadas las negociaciones, dificultando el acuerdo.

1. Por otra parte, el artículo 6 de la Ley 782 de 2002, que modificó al artículo 15 de la Ley 418 de 1997, establecía que los menores que tomaran parte del conflicto como miembros de estos grupos armados, no serían tomados como partícipes, sino como víctimas. Es decir, se resaltaba que la participación de menores en el conflicto era un delito $\mathrm{y}$, por consiguiente, los menores partícipes no eran miembros de los grupos armados, sino víctimas de estos (Universidad Nacional de Colombia, 2009).

De igual forma, en el contenido del mismo artículo, se recuerda que toda persona de la población civil que hubiese sufrido daño o deterioro en su integridad física o mental, sus bienes o hubiese sido obligado a desplazarse, como consecuencia de los actos violentos propios del conflicto interno y de sus partes, será tenido como víctima.

2. Siguiendo la misma línea, el artículo séptimo establece la obligación, a cargo del Estado, de brindar asistencia humanitaria a las víctimas del conflicto armado, siendo la Red de Solidaridad ${ }^{8}$ Social el organismo estatal que debía liderar dicha entrega de asistencia. De igual forma, el artículo octavo pone en manos del Instituto Colombiano de Bienestar Familiar brindar asistencia a todos los menores que sean víctimas del conflicto interno, ya sea porque hayan tomado parte en este, o porque hayan sido blanco de la violencia política en el marco del conflicto armado.

Dentro del mismo tema, el artículo décimo establece que la asistencia médica y hospitalaria urgente que corresponde a las víctimas de los atentados terroristas, combates o masacres, debe ser brindada de manera obligatoria por todas las entidades -tanto públicas como privadas- que prestan servicios de salud, sin que dichas entidades puedan poner condiciones previas para su atención. A continuación, el artículo once determina que el pago del costo que generen dichos servicios se hará por conducto del Ministerio de Salud, tomando para ello recursos provenientes del Fondo de Solidaridad y Garantía del Sistema General de Seguridad Social en Salud (Fosyga).

8 Estamento público de orden nacional creado con el fin de financiar y coordinar los programas de ayuda a los sectores de la población más desfavorecidos. 
En este mismo sentido, el articulado subsiguiente establece que para apoyar a las víctimas del conflicto, una serie de ayudas de tipo financiero deben ser puestas a disposición de los afectados, bajo control y ayuda de la Red de Solidaridad Social.

3. Otro punto que causó revuelo fue la capacidad otorgada por el artículo diecinueve, de permitir la desmovilización individual de los miembros de los grupos armados al margen de la ley. Es decir, para acogerse a los beneficios de la entrega de armas, no se hacía necesario que un grupo entero se desmovilizara, sino que cada combatiente podía abandonar sus actividades como miembro de dicho grupo individualmente, y acercarse de manera personal al Estado para solicitar un indulto por sus delitos, mientras que demostrara su voluntad de reincorporarse a la vida civil.

Los detractores de la norma alegaron que dicho inciso favorecía la impunidad, ya que permitía que aquellos que hubiesen cometido crímenes de todo tipo consiguieran un indulto estatal simplemente acogiéndose al programa de desmovilización. Para zanjar el asunto, la Corte Constitucional Colombiana se vio obligada a pronunciarse sobre este tema, determinando mediante su Sentencia C-928 de 2005, la validez del inciso, siempre y cuando se entendiera que lo que podía perdonarse por esta vía eran, únicamente, los delitos políticos y delitos conexos a estos.

\section{Decreto 128 de 2003}

Iniciando el 2003 el Gobierno nacional emitió el Decreto 128 de 2003, que tenía como fin complementar el contenido y reglamentar la aplicación de la Ley 418 de 1997, que había sido reformada y mantenida vigente por la Ley 782 de 2002 . De manera específica, el Decreto 128/03 busca reglamentar el proceso de desmovilización al que pueden acogerse los miembros de los grupos al margen de la ley, con intención de regresar a la vida civil. Para lograr tal fin el Decreto establece:

1) El artículo segundo define el concepto de desmovilizado y reincorporado. A saber: el primero es aquel miembro de los grupos armados ilegales que decide dejar las armas y se entrega al Estado. El segundo, es el desmovilizado que ya ha sido certificado por el Comité Operativo para la Dejación de Armas ${ }^{9}$ (CODA). Autoridad creada por el mismo Decreto y que tiene como fin avalar y certificar la desmovilización, de quien se encuentra en proceso de reincorporación a la vida civil.

2) Artículo tercero y cuarto: se instauran las pautas del proceso de desmovilización. El proceso se inicia con la entrega voluntaria del miembro de los grupos armados ilegales frente a una autoridad legítima, sea un juez, un fiscal, una autoridad territorial, una autoridad militar o un representante de la Procuraduría o la Defensoría del Pueblo. Luego el desmovilizado pasará a

$9 \quad$ Este Comité es el encargado de expedir el código de identificación para personas en proceso de reintegración. Esta certificación permite el ingreso del desmovilizado al proceso de reincorporación y el otorgamiento a su favor, de los beneficios jurídicos y socioeconómicos. 
manos del Ministerio de Defensa, ente que deberá propender por su bienestar, para luego entregarlo al Ministerio del Interior que se hará cargo del proceso de reincorporación.

Posteriormente, con la aparición del Decreto Nacional 1391 de 2011, el Ministerio del Interior sería remplazado en esta función por la Alta Consejería Presidencial para la Reintegración Social y Económica de Personas y Grupos Alzados en Armas.

3) En los artículos quinto y sexto, se establecen los derechos del desmovilizado englobados en la protección de sus derechos humanos, su integridad física y su dignidad, la garantía de un debido proceso, la entrega de ayuda humanitaria y los beneficios económicos establecidos por la normativa.

Beneficios recibidos por el desmovilizado durante el proceso. Artículos sexto, séptimo y octavo: El desmovilizado contará con una identificación y los documentos necesarios para ello, como son la libreta militar, la cédula y el certificado de antecedentes judiciales. Gozará de atención médica para él y su grupo familiar y además contará con la garantía de su seguridad personal y la de sus familiares.

4) Se establece la composición y las funciones del Comité Operativo para la Dejación de Armas - CODA en los artículos once y doce. Esta entidad tendrá la finalidad de recibir, evaluar y certificar la solicitud del desmovilizado para dejar las armas y reincorporarse a la vida civil. Para esto, deberá evaluar las circunstancias del abandono voluntario de las armas, al igual que la voluntad de este para reincorporarse a la sociedad. Una vez constatada la pertenencia del individuo a un grupo armado al margen de la ley, y comprobada su voluntad de reincorporación, el CODA certificará estos elementos y el desmovilizado pasará a convertirse en un reincorporado.

5) Beneficios del Reincorporado, artículos trece al veintiuno. El reincorporado recibirá múltiples beneficios encaminados a ayudarlo en su proceso de reintegración a la vida civil. Entre estos tendrá beneficios jurídicos (derecho al indulto), económicos (apoyo económico y financiación de proyectos de creación de empresa), educativos (acceso a la educación básica, media, técnica o tecnológica) y laborales (bolsa de empleo y contratación para reincorporados), al igual que otros servicios especiales y un seguro de vida por duración de un año.

6) Protección y atención especial al menor desmovilizado, artículos veintidós a veinticinco. En desarrollo del contenido de la Ley 782 de 2002 sobre la condición de víctima del menor miembro de los grupos armados ilegales, el Decreto 128 de 2003 establece un procedimiento diferenciado, a cargo del Instituto de Bienestar Familiar - ICBF, para la entrega y desmovilización de menores que se encuentran en esta situación, buscando garantizar su bienestar y que reciban la ayuda social, económica y psicológica necesaria para una reincorporación adecuada a la vida civil. 
El mecanismo de desmovilización contenido en el Decreto 128 de 2003 fue duramente criticado por diversos sectores de la sociedad civil y defensores de los derechos humanos, bajo la premisa que en lugar de facilitar la paz promovía la impunidad (Comisión Colombiana de Juristas, 2005). El principal argumento esgrimido en este sentido era que la desmovilización individual no garantizaba en ninguna medida el fin del conflicto, ni la disolución de los grupos armados ilegales, pero sí permitía que sus miembros, de manera individual, se acogieran al indulto. A juicio de los detractores, solo la desmovilización colectiva y masiva de los grupos armados al margen de la ley podría garantizar la atenuación del conflicto y, por consiguiente, solo se justificaba el indulto en este tipo de procesos colectivos.

\section{Decreto 2767 de 2004}

En agosto de 2004 el Gobierno nacional emitió un nuevo decreto, que adicionaba beneficios de carácter opcional para el desmovilizado y que se sumaban a los beneficios ya mencionados en el Decreto 128 de 2003.

Beneficios por colaboración, artículo segundo: a los desmovilizados que en el momento de su entrega aportaran información acertada que permitiera esclarecer delitos o evitar su cometido, les sería otorgada una bonificación económica adicional que recibirían después de obtener su certificación por parte del CODA. Dicha bonificación sería proporcional al resultado obtenido a partir de la información presentada.

Beneficios por entrega de material, artículo tercero: de manera similar al inciso anterior, el desmovilizado que al momento de presentarse hiciera entrega de material de guerra, comunicaciones, intendencia o similares, drogas ilegales, insumos o maquinaria para la fabricación de las mismas, recibiría una bonificación económica adicional, una vez obtenida la certificación de su condición por parte del CODA.

De igual forma, el artículo cuarto del mencionado Decreto abría la puerta a otro tipo de bonificaciones económicas adicionales, derivadas de la colaboración activa que el desmovilizado prestara al Gobierno y a las Fuerzas Militares.

\section{Ley 795 de 2005: Ley de Justicia y Paz}

Sin lugar a dudas, dentro del conjunto normativo que permitió la desmovilización de los grupos paramilitares, el elemento de mayor importancia es la Ley 795 de 2005, también llamada "Ley de Justicia y Paz". Si bien con la entrada en vigencia del Decreto 128 de 2003 empezaron a presentarse grandes desmovilizaciones de grupos de autodefensas, no fue hasta la aparición de la Ley 795 de 2005 que se pudo concertar la desmovilización colectiva de las Autodefensas Unidas de Colombia AUC, organización que reunía al grueso de los grupos paramilitares presentes a lo largo del territorio nacional. 
Duramente criticada por sus concesiones a los grupos paramilitares (Forero, 2005) y sometida a múltiples revisiones por diversos estamentos, incluyendo un amplio número de sentencias de la Corte Constitucional Colombiana que alteraron algunos de sus apartes, se hace obligatorio el análisis de su contenido para entender su importancia y alcance, al igual que para comprender la esencia del proceso de desmovilización colectiva de los grupos paramilitares que tuvo lugar en el $2005 \mathrm{y}$ 2006. Dentro del texto de los 72 artículos que conforman la Ley, es necesario resaltar:

1) Objetivos, artículo primero: La Ley de Justicia y Paz establece que su objetivo directo es el facilitar los procesos de paz con los grupos al margen de la ley y la correspondiente reintegración a la vida civil de sus integrantes. Resaltando, una vez más, el hecho de que el proceso de desmovilización puede ser de forma grupal o individual. De igual manera, se busca que en el desarrollo de este objetivo se garanticen siempre los derechos de las víctimas.

Si bien la norma se hizo en el marco de las negociaciones con los grupos paramilitares, el artículo establece que puede ser aplicada por igual a dichos grupos, o a los grupos insurgentes (guerrillas) que también operan en el interior del país, ateniéndose así a la definición de grupo al margen de la ley dada por la Ley 782 de 2002.

2) Alternatividad Penal, artículo tercero: se establece la capacidad de suspender las penas instauradas mediante sentencia judicial, remplazándolas por penas alternativas, en razón de la contribución del beneficiario en la consecución de la paz, la colaboración con la justicia y la reparación de las víctimas.

3) Derechos de las víctimas y de los desmovilizados, artículo cuarto: queda establecido que dentro del proceso de desmovilización de los grupos armados al margen de la ley se debe tener siempre en cuenta el interés de las víctimas, su derecho a la verdad, la justicia y la reparación. De igual forma, se debe asegurar el derecho al debido proceso y las garantías judiciales de los procesados.

4) Concepto de los derechos a la verdad, la justicia y la reparación, artículos sexto a octavo: Los mencionados derechos de las víctimas deberán entenderse de la siguiente forma:

- Derecho a la verdad: tanto las víctimas como la sociedad en general tienen derecho a conocer la verdad de lo ocurrido en el conflicto y conocer la verdad sobre los delitos cometidos por los grupos armados que se encuentren en proceso de desmovilización. De igual forma, debe darse a conocer el paradero de los secuestrados y desaparecidos.

- Derecho a la justicia: el Estado, en razón de un proceso de desmovilización, no puede desconocer o suprimir su función de investigar de manera plena y efectiva los delitos cometidos por los miembros de los grupos armados ilegales, buscando de igual forma la reparación de las víctimas de dichos delitos, y la no repetición de estos. 
- Derecho a la reparación: el derecho a la reparación abarca un abanico de acciones, tales como la restitución de bienes y terrenos, la indemnización de daños económicos, la rehabilitación de daños físicos y psicológicos, y el restablecimiento de la dignidad de las víctimas mediante la satisfacción o compensación moral. De igual forma, debe garantizarse que las conductas lesivas que los afectaron no vuelvan a tener lugar.

5) Requisitos para la desmovilización, artículos décimo y once: se establecen, de forma concisa, los requisitos que deben cumplirse para poder acceder a la desmovilización y sus correspondientes beneficios, tanto a nivel colectivo como a nivel individual. En términos generales, se busca garantizar el cese completo de las actividades delictivas y la no reincidencia por parte de los desmovilizados.

6) Principios procesales, artículos doce a quince: se establecen las bases que fundamentan el proceso judicial contra los desmovilizados, a saber: oralidad, celeridad, defensa y esclarecimiento de la verdad. Es decir, se busca que las audiencias sean rápidas, que el investigado tenga derecho a un defensor (sea de confianza o público) y que mediante esta actividad judicial se logre el esclarecimiento completo de los hechos delictivos en los que haya tomado parte el desmovilizado, garantizando de esta forma el mencionado derecho de las víctimas a la verdad. De igual manera, es obligación del Estado velar por la integridad de todos los testigos, víctimas y peritos que tomen parte en los procesos judiciales.

7) Investigación y juzgamiento, artículos dieciséis a veintiocho: la investigación de los procesos de desmovilización corresponderá a la Unidad Nacional de Fiscalía para la Justicia y la $\mathrm{Paz}^{10}$, entidad que asignará a los fiscales delegados que deberán llevar adelante las investigaciones pertinentes. Por su parte, el juzgamiento de los casos quedará, de forma exclusiva sin posibilidad de conflicto de competencia, en manos de los Tribunales Superiores de Distrito Judicial, según reparto realizado por el Consejo Superior de la Judicatura.

Dentro del proceso de juzgamiento cada desmovilizado deberá rendir versión libre y espontánea, frente al fiscal delegado encargado de su caso, en la cual deberá dar cuenta de todos los hechos delictivos en los que haya tomado parte en razón de su militancia en los grupos armados, al igual que la fecha de su entrada a los mismos y, en caso de tenerlos, de todos los bienes que tenga en su poder y que permitan la reparación de las víctimas. Recibida

10 Creada por la Ley 975/05, es la encargada de investigar, por conducto del fiscal delegado para el caso, con el apoyo del grupo especializado de policía judicial, las circunstancias de tiempo, modo y lugar en que se realizaron las conductas punibles; las condiciones de vida, sociales, familiares e individuales del imputado o acusado y su conducta anterior; los antecedentes judiciales y de policía, y los daños que individual o colectivamente haya causado de manera directa a las víctimas, tales como: lesiones físicas o sicológicas, sufrimiento emocional, pérdida financiera o menoscabo sustancial de derechos. 
la declaración, corresponde a la Unidad Nacional de Fiscalía para la Justicia y la Paz, mediante su fiscal delegado, en conjunto con la Policía Judicial, comprobar la veracidad del testimonio presentado, esclareciendo todos los hechos que hagan parte de mismo.

Una vez compilado el material probatorio correspondiente que permita inferir la participación del desmovilizado en uno o varios hechos delictivos, el fiscal delegado, con autorización del magistrado que ejerce como juez de control de garantía, procederá a solicitar la audiencia de imputación, en la cual además de la imputación fáctica también se establecerán las medidas de detención preventiva del imputado, en los centros previamente establecidos para el proceso de desmovilización, y las medidas cautelares sobre los bienes presentados para la reparación de las víctimas.

El proceso de investigación en manos de la Unidad Nacional de Fiscalía para la Justicia y la Paz, y de la Policía Judicial, deberá continuar una vez realizada la imputación en aras de esclarecer por completo lo sucedido y, en un plazo no mayor a sesenta días a partir de la imputación, debe solicitar al magistrado que ejerce como juez de garantías que se proceda a la audiencia de formulación de cargos. En esta audiencia, y tras escuchar los pronunciamientos del fiscal el acusado asistido por su defensor, podrá aceptar los cargos. Si el magistrado encargado establece que esta confesión ha sido libre, voluntaria y espontánea, procederá entonces a fijar fecha para la audiencia de sentencia.

En caso de que el desmovilizado no acepte los cargos, será obligación de la Unidad Nacional de Fiscalía para Justicia y Paz remitir su caso a la autoridad que resulte competente, de acuerdo con la fecha y la naturaleza de los delitos investigados. En caso de que se haga una aceptación parcial de los cargos, la parte aceptada será juzgada bajo la Ley de Justicia y Paz, y los cargos que no hayan sido aceptados serán enviados a la autoridad competente.

Si en el momento de la desmovilización el investigado ya tenía investigaciones penales vigentes o se le había formulado acusación, este podrá - asistido por un defensor durante el proceso anteriormente mencionadoaceptar también dichos cargos de manera libre y espontánea, frente al magistrado que haga la función de control de garantías.

Respecto de la sentencia condenatoria emitida al final de proceso, esta deberá fijar tanto la pena principal como las posibles penas accesorias. De igual forma, se incluirán en el fallo la pena alternativa establecida por la Ley de Justicia y Paz, y los compromisos de comportamiento por el término que el tribunal determine. Finalmente, se incluirán en la sentencia las obligaciones de reparación económica y moral de las víctimas, y la extinción del dominio de los bienes que serán destinados a la reparación de las mismas. 
8) Incidente de Reparación Integral ${ }^{11}$, artículo veintitrés: además de las diligencias ya mencionadas, durante la audiencia en la que se declare la legalidad de la aceptación cargos, a solicitud de la víctima, del Ministerio Público o del fiscal del caso, el magistrado ponente deberá dar lugar al incidente de reparación integral en audiencia pública que se efectuará dentro de los cinco días siguientes. En dicha audiencia, la víctima -directamente o mediante representante legal- expresará de manera concreta el modo de reparación que pretende. La Sala solo podrá inadmitir la pretensión si quien la promueve no es una víctima o sí la única pretensión fuera la del pago de perjuicios y dicho pago ya se encontrara acreditado.

Admitida la pretensión, la sala la pondrá en conocimiento del imputado e invitará a las partes a conciliar. En caso de que de la conciliación surja un acuerdo, este deberá incorporarse en la decisión que falla el incidente. Si no hay lugar a un acuerdo, se dispondrá la práctica de la prueba ofrecida por las partes, se oirá el fundamento de sus respectivas pretensiones y en el mismo acto se fallará el incidente. La decisión que se tome en uno u otro sentido deberá incorporarse a la sentencia condenatoria.

9) Pena Alternativa, artículo veintinueve: una vez establecida la pena por parte de la Sala del Tribunal Superior de Distrito en que haya recaído el caso y según lo establecido por el Código Penal, si se han cumplido a cabalidad las condiciones establecidas por la Ley de Justicia y Paz, la Sala impondrá una pena alternativa que consiste en privación de la libertad por un período mínimo de cinco años y no superior a ocho años, tasada de acuerdo con la gravedad de los delitos cometidos y con la colaboración efectiva del desmovilizado en el esclarecimiento de los mismos.

Para tener derecho a esta pena alternativa, se requerirá que el beneficiario se comprometa a contribuir con su resocialización a través del trabajo, estudio o enseñanza durante el tiempo que permanezca privado de la libertad, así como a promover actividades orientadas a la desmovilización del grupo armado al que pertenecía.

Una vez se haya cumplido la pena alternativa, el beneficiario quedará en situación de libertad condicional por un término igual a la mitad de la pena que le fue impuesta, periodo en el cual no debe incurrir en ningún tipo de delito y debe notificarse periódicamente frente al Tribunal que le corresponde, manteniéndolo siempre informado de su lugar de residencia. Una vez terminado este periodo de prueba, y si ha cumplido con todas las condiciones mencionadas, se dará por extinta la pena principal. Si por el

11 Hace referencia a la fase incidental y subsiguiente al juicio oral que ha concluido con fallo, que declara la responsabilidad penal del acusado, se inicia a solicitud de la víctima, del físcal o del Ministerio Público por petición de ella, con el propósito de obtener la reparación de los daños y perjuicios que se le hayan causado con el delito. 
contrario, el beneficiario incumple sus compromisos, se revocará la libertad a prueba y deberá cumplir la pena inicialmente determinada.

10) Derechos de las víctimas durante el proceso y frente a la administración de justicia artículos treinta y siete a cuarenta y uno: además de los ya mencionados derechos generales de las víctimas, estas deben contar con otros derechos anexos frente a la administración de justicia en los procesos llevados contra sus victimarios. Estos derechos abarcan:

- El adecuado e inmediato acceso a la administración de justicia que incluye la protección de su dignidad, intimidad, la garantía de su seguridad, la reparación pronta e integral de los daños sufridos, ser oídas como parte de los procesos, que se les facilite el aporte de pruebas a los mismos, recibir la información pertinente para la defensa de sus intereses, ser informadas sobre las decisiones que tomen los jueces y sobre los recursos a los que tienen derecho, ser asistidas por un abogado de confianza o por un funcionario público, recibir asistencia integral para su recuperación y, finalmente, en caso de ser necesario, poder contar con un traductor.

- Protección a víctimas y testigos: es preciso que los funcionarios estatales que formen parte en estos procesos tomen todas las medidas necesarias para proteger la seguridad, el bienestar físico y psicológico, la dignidad y la vida privada de las víctimas y los testigos, así como la de las demás partes del proceso.

- Excepción a la publicidad en el juicio: si bien por definición general los juicios tienen un carácter público, el Tribunal encargado puede establecer excepciones con la intención de proteger a las víctimas, los testigos o incluso al acusado, y realizar parte del juicio a puerta cerrada. De igual forma, puede recurrir a la herramienta del testimonio mediante audiovideo, permitiendo siempre el ejercicio del derecho de contradicción y confrontación de las partes.

- Medidas previas de protección: cuando la publicidad de elementos materiales probatorios, evidencia física o información obtenida, entrañe peligro grave para la seguridad de un testigo o la de su familia, el fiscal deberá abstenerse de presentarlos en cualquier diligencia anterior al juicio, y en su reemplazo hará un resumen de dichos elementos de conocimiento; sin embargo, esto en ningún momento podrá convertirse en un obstáculo para ejercer el derecho al debido proceso que tiene el acusado.

11) Derecho a la reparación de las víctimas, artículos cuarenta y dos a cincuenta y cinco. Como ya se ha comentado anteriormente, la víctima tiene derecho a una reparación plena, rápida e integral. La obligación de esta reparación, a su vez, recae tanto sobre los miembros de los grupos armados ilegales, como sobre el Estado. Si bien la reparación tiene, en gran medida, un contenido económico, no debe limitarse la misma al simple pago pecuniario de los 
daños causados, si no que la reparación integral debe estar enfocada por igual a la restitución, indemnización, rehabilitación (médica y psicológica) y satisfacción de las víctimas.

Dentro de este entendido, la reparación abarcará, además de los pagos y la entrega de bienes, los actos públicos destinados tanto a reconocer el daño que se ha causado a las víctimas, como a restablecer la dignidad de las mismas, solicitando su perdón y realizando compromisos de no repetición. De igual forma, se entenderá como parte de la reparación la información que lleve a determinar el estado y la ubicación de los secuestrados y desaparecidos, al igual que la localización de los cadáveres de las víctimas del conflicto, de tal forma que puedan completarse los procesos de duelo de las familias.

12) Conservación de archivos, artículos cincuenta y seis a cincuenta y ocho. En cumplimiento del deber a la preservación de la memoria histórica ${ }^{12}$, que corresponde al Estado como parte de los procesos de desmovilización, se establecerán archivos en los cuales se consigne y preserve de forma adecuada el conocimiento de la historia de la causa, desarrollo y consecuencias de las acciones de los grupos armados. Debe, igualmente, garantizarse un adecuado y fácil acceso a dichos archivos, tanto a las víctimas como a todos aquellos interesados en la investigación histórica de lo sucedido.

13) Acuerdos Humanitarios, artículos cincuenta y nueve a sesenta y uno. Considerando que la paz es un derecho de todos los habitantes de Colombia, y que por tanto es obligación del Estado la búsqueda de esta, se refrenda la capacidad que tiene el Gobierno de autorizar a sus representantes o voceros para adelantar los contactos que permitan llegar a acuerdos humanitarios con los grupos armados organizados al margen de la ley.

\section{B. Análisis de sentencias de la Corte Constitucional}

Durante la última década, y con ocasión del marco legal antes referido, la Corte Constitucional de Colombia ha venido emitiendo una serie de sentencias que revisan dicho contenido normativo, al tiempo que dan las pautas constitucionales para su interpretación y aplicación. De igual forma, este contenido jurisprudencial ha hecho claridad sobre conceptos fundamentales como los de víctima y sus derechos, o sobre la verdadera naturaleza de la reparación y de las penas alternativas.

12 Viene a designar el esfuerzo consciente de la humanidad por encontrase con su pasado, sea este real o imaginado, valorándolo y tratándolo con especial respeto. En Colombia se ha creado el Centro de Memoria Histórica con el objeto de reunir y recuperar todo el material documental, testimonios orales y por cualquier otro medio relativos a las violaciones de que trata el artículo 147 de la Ley de Víctimas y Restitución de Tierras. La información recogida será puesta a disposición de los interesados, de los investigadores y de los ciudadanos en general, mediante actividades museísticas, pedagógicas y cuantas sean necesarias para proporcionar y enriquecer el conocimiento de la historia política y social del país. 
De ahí que su revisión se haga indispensable en cualquier estudio sobre el proceso de Justicia y Paz. Entre las muchas sentencias que este cuerpo colegiado emitió sobre el tema, resulta importante resaltar las siguientes:

\section{Sentencia C-928 de 2005}

Magistrado ponente: Jaime Araujo Rentería

Expediente: D-5703

Fecha: 6 de septiembre de 2005

Norma revisada: Ley 782 de 2002, artículo 19

Problema jurídico: ¿Se puede conceder indulto, de manera individual, a aquellos individuos que de forma independiente hayan dejado las filas de los grupos armados al margen de la ley?

Posición de la Corte: Sí.

Argumentos de la Corte: Si bien el ideal de un proceso de indulto y desmovilización es que sea colectivo y que implique el cese de actividades ilegales de un grupo armado completo, no puede ni debe evitarse que cada miembro de dichos grupos tenga la posibilidad de dejar las armas y reincorporarse a la vida civil de forma independiente. Sin embargo, la Corte Constitucional argumenta que el indulto concedido de forma individual debe atenerse igualmente al contenido constitucional, por lo cual, solo pueden ser indultados los delitos políticos y los delitos conexos con aquellos.

\section{Sentencia C-370 de 2006}

Magistrado ponente: Sala Plena

Expediente: D-6032

Fecha: 18 de mayo de 2006

Norma revisada: Ley 795 de 2005

Problema jurídico: múltiple, se citarán los de mayor trascendencia.

Problema jurídico 1: La alternatividad penal establecida para los desmovilizados ¿Resulta contraría a la Constitución Política, generando impunidad y violando los derechos de las víctimas?

Posición de la Corte: No.

Argumentos de la Corte: La alternatividad penal establecida por el artículo tercero de la Ley 795 de 2005 resulta factible, en la medida en que se entienda que los desmovilizados se encuentran obligados a colaborar con la justicia para garantizar los derechos de las víctimas a la verdad, la justicia y la reparación y a la no repetición 
de sus delitos para conservar el derecho a dicha alternatividad. Además se debe tener en cuenta la situación particular de cada combatiente, diferenciando entre: 1. Los que al momento de su desmovilización no tengan procesos penales en curso ni condenas en su contra. 2. Cuando se trata de combatientes que estén siendo procesados o hayan sido condenados por los delitos de sedición, asonada y rebelión (incluyendo los delitos conexos). 3. Cuando se trata de combatientes que tengan procesos penales en curso o condenas en contra por delitos distintos a los políticos y conexos.

Problema jurídico 2: ¿Solo pueden ser consideradas como víctimas por extensión a los familiares en primer grado de la víctima directa?

Posición de la Corte: No.

Argumentos de la Corte: La expresión "en primer grado" contenida en el artículo quinto de la Ley 795 hace referencia a una presunción que no excluye, en ningún momento, como víctimas a otros familiares que hubieren sufrido un daño como consecuencia de cualquier tipo de conducta violatoria de la ley penal cometida por miembros de grupos armados al margen de la ley.

Problema jurídico 3: ¿Solo debe darse cuenta en el proceso de desmovilización de la entrega y liberación de los secuestrados?

Posición de la Corte: No.

Argumentos de la Corte: Si bien el numeral sexto del artículo décimo de la Ley 795 de 2005 establece como requisito para acceder a los beneficios de la desmovilización la entrega de los secuestrados que estén en poder de aquellos que quieran desmovilizarse, debe considerarse que, anexa a esta obligación, es indispensable que se dé cuenta de la situación y ubicación de los desaparecidos.

Problema jurídico 4: ¿Resulta obligatoria la entrega de bienes por parte de los desmovilizados?

Posición de la Corte: Sí.

Argumentos de la Corte: La entrega de bienes por parte de los desmovilizados está circunscrita a los bienes que hayan sido fruto de su accionar ilegal, al estar estos bienes enfocados a la reparación de las víctimas, es un compromiso ineludible de aquellos que se acogen a la Ley de Justicia y Paz el presentar activos, ya sea en forma de capital, terrenos, entre otros, que permitan satisfacer este derecho de las víctimas. Ya que la no reparación de estas representaría, desde un principio, el incumplimiento de los requisitos para acceder a los beneficios de la norma y, por lo tanto, imposibilitaría todo el proceso. Por consiguiente, resulta obligatoria la entrega de bienes encaminados a la reparación de las víctimas por parte de los desmovilizados. 
Problema jurídico 5: ¿Es necesario que se determine el origen ilegal de los bienes de los desmovilizados tendentes a garantizar la reparación de las víctimas para que se puedan establecer medidas cautelares sobre los mismos?

Posición de la Corte: No.

Argumentos de la Corte: Como ya se mencionó, la reparación de las víctimas es un compromiso ineludible. Por consiguiente, y en aras de la celeridad del proceso y la garantía de los derechos de las víctimas, no es necesario que un juez espere la declaración del origen ilegal de los bienes de un desmovilizado para que pueda imponer sobre los mismos las medidas cautelares necesarias.

Problema jurídico 6: ¿Puede el juez ejercer algún control sobre la aceptación de cargos que hayan realizado aquellos que buscan acceder a los beneficios de Justicia y Paz?

Posición de la Corte: Sí.

Argumentos de la Corte: Además de, según menciona la norma, revisar que dichas declaraciones se hayan presentado de forma libre, voluntaria y espontánea y bajo la asesoría de un abogado, el juez también controlará que la calificación jurídica corresponda a los hechos que obran en el expediente, velando de esta forma por el derecho a la verdad.

Problema jurídico 7: ¿Una vez concedida la pena alternativa, pueden perderse los beneficios obtenidos después de la desmovilización?

Posición de la Corte: Sí.

Argumentos de la Corte: La pena alternativa se establece bajo la premisa de la no repetición. Por consiguiente, aquellos desmovilizados que reincidan en la actividad delictiva, sea de la misma índole o de otra, perderán los beneficios obtenidos con su acogimiento a la Ley de Justicia y Paz, y deberán pagar penas completas por sus delitos.

De igual forma, aquellos desmovilizados que hayan ocultado en la versión libre información sobre su participación en delitos y la comisión de actos ilegales relacionados directamente con su pertenencia y como miembro del grupo, perderán los beneficios que hayan obtenido, y deberán cumplir con su responsabilidad penal.

Sin embargo, también establece la norma que podrá seguir siendo acreedor de los beneficios aun habiendo omitido información. Si acepta oralmente o por escrito de manera libre y espontánea su participación en el delito, siempre y cuando la omisión en su declaración no haya sido intencional, podrá seguir beneficiándose con la pena alternativa. 
Problema jurídico 8: El tiempo de concentración que hayan pasado los desmovilizados en las zonas decretadas por el Gobierno ¿deberá ser tenido en cuenta como parte de la pena?

Posición de la Corte: No.

Argumentos de la Corte: Si bien la estancia en la zona de concentración se realizó en aras de la desmovilización, no constituye pena al no comportar una imposición coercitiva de la restricción de derechos fundamentales ni encontrarse los desmovilizados privados realmente de su libertad o de su capacidad de autodeterminación. Por lo tanto, no puede ser considerado este tiempo como parte del cumplimiento de la pena.

Problema jurídico 9: ¿La responsabilidad patrimonial de los desmovilizados es únicamente a título personal?

Posición de la Corte: No.

Argumentos de la Corte: Todos y cada uno de los miembros del grupo armado organizado al margen de la ley deben responder de manera individual con su patrimonio para indemnizar a cada una de las víctimas de los actos violatorios de la ley penal por los que fueron condenados; igualmente deberán responder, de forma solidaria, por los daños ocasionados a las víctimas por otros miembros del grupo armado al cual pertenecieron.

Problema jurídico 10: ¿Se encuentra condicionada a la disponibilidad y posibilidad la restitución de las víctimas?

Posición de la Corte: No.

Argumentos de la Corte: Tal como menciona la norma debatida, la restitución implica devolver a la víctima a la situación anterior a la violación de sus derechos. Esto incluye, entre otros, tres elementos principales: el restablecimiento de la libertad, el retorno a su lugar de residencia y la devolución de sus propiedades. Estos factores no pueden verse limitados por simple posibilidad o factibilidad, sino que son un compromiso de todo el proceso de Justicia y Paz y, por consiguiente, deberán utilizarse todos los medios disponibles para garantizar su cumplimiento.

\section{Sentencia C-575 de 2006}

Magistrado ponente: Álvaro Tafur Galvis

Expediente: D-5994

Fecha: 25 de julio de 2006

Norma revisada: Ley 795 de 2005 
Problema jurídico: Múltiple. La Corte Constitucional se atiene a lo dicho en la sentencia anterior para la mayoría de los problemas jurídicos ya tratados. Entre los elementos nuevos añadidos se incluye:

Problema jurídico 1: ¿Resulta propiciador de impunidad el hecho de que el fiscal encargado de adelantar las investigaciones contra los desmovilizados por Justicia y Paz pueda archivar dichos procesos?

Posición de la Corte: No.

Argumentos de la Corte: La capacidad de archivar procesos en los cuales no se pueda probar la existencia del hecho punible, o donde el hecho evidenciado no pueda ser caracterizado como punible, es propia de todos los fiscales en la ejecución de sus funciones. Sin embargo, tal caracterización debe hacerse de manera objetiva (como corresponde a todo el ejercicio de la actividad de la fiscalía), y en el caso de Justicia y Paz, es indispensable que la decisión del archivo de las diligencias deba estar motivada, al igual que comunicada al denunciante y al Ministerio Público para el ejercicio de sus derechos y presentación de los recursos a que hubiere lugar.

\section{Sentencia C-1199 de 2008}

Magistrado ponente: Nilson Pinilla Pinilla

Expediente: D-6992

Fecha: 4 de diciembre de 2008

Norma revisada: Ley 795 de 2005

Problema jurídico 2: ¿Los servicios sociales brindados por el Gobierno a las víctimas, de conformidad con las normas y leyes vigentes, hacen parte de la reparación y de la rehabilitación?

Posición de la Corte: No.

Argumentos de la Corte: A juicio de la Corte se considera que los servicios sociales, entendidos como parte de la reparación, tendrían el efecto negativo de abrir la posibilidad de que la reparación debida se vea reducida por efecto de los servicios sociales de los que las víctimas hubieran sido beneficiarias, al punto que, en casos concretos, algunas víctimas podrían no recibir suma o prestación alguna por concepto de reparación e, incluso, que algunas de ellas vinieran a ser deudoras del Gobierno que hubiese provisto los referidos servicios. De presentarse, cualquiera de estas situaciones lesionaría el derecho de las víctimas a la reparación integral, dentro del contexto de justicia transicional. Es por esto que debe entenderse que la asistencia social que el Estado social de derecho debe a todos sus habitantes, no puede ser considerada como parte de la reparación a la que son acreedoras todas las víctimas. 


\section{JUSTICIA TRANSICIONAL}

\section{A. Aproximación al concepto}

Durante la última década, a partir del controvertido proceso de desmovilización de los grupos paramilitares realizado durante el gobierno de Álvaro Uribe Vélez, la figura de la Justicia Transicional se ha convertido en un término de recurrente mención dentro del panorama social y jurídico colombiano. El actual proceso de paz con las Fuerzas Armadas Revolucionarias de Colombia ${ }^{13}$ (FARC) ha mantenido esta tendencia y la expresión "Justicia Transicional" aparece de manera constante en los medios de comunicación y los comunicados estatales. Sin embargo, y a pesar del repetido uso del concepto, existe muy poca claridad sobre la naturaleza y características de este, al punto en que el término parece más -una suerte de comodín-.

Es por esto que, para hablar con propiedad sobre Justicia Transicional es necesario hacer claridad sobre su definición y los alcances de dicho concepto, e identificar sus características más representativas. Sin embargo, esto último no resulta fácil, ya que la misma estructura del concepto busca que sea una herramienta flexible y adaptable a situaciones diversas de conflicto y de violaciones masivas de derechos humanos. Esta amplitud de aplicación hace difícil una conceptualización estricta.

Se puede decir que la Justicia Transicional es una herramienta que busca poner fin a situaciones de conflicto interno y de violaciones masivas de derechos humanos y que persigue no solo la simple terminación de las agresiones, sino que además pretende la restauración del tejido social y la reincorporación a la vida civil de las partes del conflicto (Teitel, 2000).

Por tanto, más que una herramienta de carácter jurídico o político, la Justicia Transicional debe ser considerada un instrumento de carácter social. Esta posición es compartida por el Centro Internacional para la Justicia Transicional ${ }^{14}$ - ICTJ, entidad internacional cuya finalidad es dar asesoría y brindar apoyo a pueblos en situaciones de conflicto interno y de violación masiva de derechos humanos, para que superen estas situaciones negativas mediante la aplicación de esquemas de Justicia Transicional. En palabras de dicha organización, este instrumento puede ser definido de la siguiente manera:

13 El proceso de paz con las FARC tuvo su inicio formal el 18 de octubre de 2012, fundamentadas en el Acuerdo General para la terminación del conflicto y la construcción de una paz estable y duradera. $\mathrm{Su}$ objetivo según el gobierno es la terminación del conflicto y según las FARC el "buscar la paz con justicia social por medio del diálogo", actualmente los diálogos de paz se desarrollan en La Habana, Cuba.

14 Centro es una organización internacional sin ánimo de lucro cuya finalidad es tratar de ayudar a sociedades en proceso de transición a enfrentarse al legado de violaciones masivas de los derechos humanos y a desarrollar la confianza ciudadana en la capacidad de las instituciones públicas para proteger esos derechos, a través de la formación técnica y la transmisión de conocimiento de experiencias afines registradas en otros lugares del mundo. 
La Justicia Transicional no es un tipo especial de justicia sino una forma de abordarla en épocas de transición desde una situación de conflicto o de represión por parte del Estado. Al tratar de conseguir la rendición de cuentas y la reparación de las víctimas, la justicia transicional proporciona a las víctimas el reconocimiento de sus derechos, fomentando la confianza ciudadana y fortaleciendo el Estado de derecho (ICTJ, 2014).

La anterior definición, a pesar de poseer un carácter general, resulta bastante completa y permite evidenciar los principales elementos que caracterizan a la Justicia Transicional: su carácter social, la inclusión de elementos tanto judiciales como no judiciales, la búsqueda de claridad sobre lo ocurrido, el reconocimiento y reparación de las víctimas y la consolidación del Estado de Derecho, que a su vez se convierte en un garante de la no repetición de lo ocurrido.

Además de insistir en la naturaleza social de la herramienta, trasciende el simple campo de lo jurídico, y a pesar de conservar un carácter amplio, añade nuevos elementos importantes que diferencian a la Justicia Transicional de un simple proceso de indulto o amnistía, o de un acuerdo tradicional de paz, como la rendición de cuentas que debe ser presentada por las partes en conflicto y la reparación que debe hacerse a las personas que sin ser parte hayan sido víctimas de la situación de agresión o vulneración de derechos.

\section{B. Alcance y naturaleza de la figura}

Más allá de perseguir simplemente la búsqueda de un castigo a los culpables u otorgar amnistías, la finalidad primordial de la Justicia Transicional es cerrar las heridas sociales que han ido dejando el conflicto interno o la represión estatal, y restablecer los derechos de la población (Cobban, 2007). Es decir, si bien esta herramienta incluye la imposición de sanciones judiciales o la condonación de penas a las partes en conflicto, su principal enfoque es la búsqueda de la reparación a la población afectada, de ahí que se resalte el carácter social de la Justicia Transicional.

Para una mayor compresión de los objetivos últimos de esta figura, se hace necesario analizar de manera individual cada uno de estos elementos, para luego ver cómo logran configurar en conjunto una adecuada terminación del conflicto y la superación de la situación de violación masiva de los derechos humanos que este acarrea.

Dentro de los procesos de Justicia Transicional debe existir, a nivel operativo, un censo de las víctimas que deben ser escuchadas y que deben tomar parte en el proceso, a la vez que se crean comisiones encargadas de velar para que salga a la luz la verdad de lo ocurrido (Roman, 2011). De igual forma, la reparación de las víctimas no debe ser vista solo desde el punto económico, sino que además debe incluir el apoyo global necesario, es de decir, apoyo médico y psicológico con el fin de ayudarles en la superación de sus aflicciones. 
Como ya se ha mencionado, uno de los presupuestos de la figura es la identificación plena de las víctimas. Resulta evidente que no puede existir una reparación de las víctimas del conflicto o de la opresión estatal si no se empieza por el reconocimiento mismo de estas. Esto no solo implica aceptar de forma general que hubo personas afectadas, si no individualizarlas y señalar de manera clara a qué afectaciones se vieron sometidas, para luego buscar activa y diligentemente el restablecimiento de los derechos que se vieron lesionados, acto conocido como Reparación. Sobre este particular, la Corte Interamericana de Derechos Humanos ${ }^{15}$ - CIDH ha establecido que las víctimas de un conflicto interno o de una situación masiva de violación de derechos humanos son titulares de tres derechos especiales que deben ser satisfechos de forma ineludible y prioritaria durante el desarrollo de procesos de Justicia Transicional: derecho a la verdad, a la justicia y a la reparación (Abuchaibe, 2012).

El derecho a la verdad, como elemento principal de la Justicia Transicional, hace alusión a la ya mencionada obligación de los actores del conflicto o perpetradores de las violaciones a los derechos humanos de la población, de reconocer su responsabilidad y reconocer a las víctimas de sus actos. Sin embargo, desde esta perspectiva se plantea no solo como un deber de los mencionados agresores, sino además como un derecho de las víctimas. Según este criterio, estas últimas tienen derecho a saber la verdad de lo ocurrido, lo que incluye el conocer el destino de los desaparecidos y secuestrados. Así, a juicio de la Corte Interamericana de Derechos Humanos, no puede existir una verdadera reparación sin que primero se satisfaga el derecho a la verdad (Quinche, 2009).

Este elemento hace referencia a la necesidad de que la verdad de lo ocurrido salga a la luz. No basta con que las partes del conflicto o los causantes de las agresiones entreguen las armas, si se desea cerrar de manera plena las heridas sociales dejadas por lo sucedido es necesario, en primer lugar, que exista una completa claridad sobre los hechos que tuvieron lugar (Cobban, 2007). Así, los actores del conflicto deben empezar por reconocer de manera abierta y completa cada uno de los actos y violaciones de derechos humanos que perpetraron. De esta forma, y al reconocer que se vulneraron los derechos humanos, se reconoce no solo la responsabilidad de los participantes, sino también la existencia de las víctimas, lo que da pie a la siguiente etapa del proceso de Justicia Transicional: La Reparación.

Hablamos del derecho a la justicia como otro de los elementos esenciales dentro de este proceso, es decir, que exista un proceso jurídico mediante el cual se asignen de forma legal las responsabilidades penales de los actores de las violaciones a los derechos humanos. Esto podría parecer contradictorio, ya que para incentivar la desmovilización de los mismos, se les confieren por norma general,

15 Órgano judicial de la Organización de Estados Americanos y la autoridad encargada de investigar y determinar la responsabilidad de los Estados parte por las supuestas violaciones de derechos humanos, una vez denunciadas por la Comisión Interamericana de Derechos Humanos u otros Estados parte. 
indultos o amnistías por lo que se suele pensar que la Justicia Transicional fomenta la impunidad. Sin embargo, esta aparente disyunción logra salvarse mediante la figura de la alternatividad penal (Roman, 2011), que ofrece beneficios tanto a los afectados como a los agresores, además de la imposición de penas alternativas como la solicitud de perdón públicamente y la reparación directa de las víctimas por parte de los agresores (Teitel, 2000).

Mediante esta figura, una vez realizados los procesos penales a los responsables y establecidas las condenas que corresponderían según la normatividad penal aplicable, se les confiere a estos el beneficio de una pena alterna de carácter reducido en extensión o de tipo social, a cambio de que se comprometan a decir la verdad de lo sucedido, reparar a las víctimas de sus actos y no reincidir en conductas delictivas. Así, resultan beneficiadas las víctimas, que ven satisfechos sus deseos de justicia formal, al tiempo que los agresores reciben el incentivo de una pena reducida y una ayuda estatal para reintegrarse a la sociedad civil.

Por lo tanto, se busca que el agresor deponga las armas a cambio de una pena reducida y una activa colaboración del Estado para lograr su reintegración a la sociedad, así como, que las víctimas vean satisfecho su derecho de justicia y su necesidad de reparación, logrando zanjarse, de esta forma, el conflicto inicial entre la necesidad de justicia de las víctimas y la necesidad de indultos o penas reducidas para impulsar la entrega y desmovilización de los actores del conflicto.

Además de lo anterior, y en los casos en que el Estado o parte de este (como el Ejército u otras instituciones estatales) haya intervenido de forma activa en el conflicto armado, se hace necesaria una restructuración de las instituciones públicas que tomaron parte en los hechos (ICTJ, 2014). Esto con una triple finalidad: en primer lugar, desmantelar la maquinaria institucional que perpetró, fomentó o permitió los abusos, en segundo lugar, contribuir a la garantía de la no repetición de las violaciones a los derechos humanos y, por último, evitar que estas instituciones partícipes se conviertan en herramienta para la obstrucción a la justicia o permitan la impunidad.

En los casos en que el Estado ha sido parte de la violación de los derechos humanos, ya sea de forma activa por el accionar de sus miembros o de forma pasiva por la omisión de sus agentes al permitir los actos lesivos de otros, se hace necesario proceder a la reestructuración y depuración de las partes del Estado que se vieron envueltas en los hechos. Esto no solo busca suprimir del cuerpo estatal las facciones que realizaron, favorecieron o permitieron en el abuso, sino que además busca evitar que dichas instituciones interfieran en el proceso de Justicia Transicional y se oculte la verdad de lo ocurrido.

Finalmente, en cuanto a la reparación de las víctimas, el concepto es bastante amplio, ya que hace alusión tanto a elementos materiales, como el pago de dinero, la prestación de servicios médicos y psicológicos y la restitución de tierras, al igual que a la aplicación de elementos de carácter simbólico, como la elevación de monumentos, la petición de disculpas públicas por parte de sus agresores y la creación de centros 
de memoria historia para que no se olvide lo sucedido (ICTJ, 2004). Para que las víctimas se sientan resarcidas por el daño sufrido, se restablezcan sus derechos y se recupere su dignidad humana.

De todo lo anterior, se puede deducir el que vendría a convertirse en el fin último de la Justicia Transicional, más allá de la simple terminación de hostilidades y violaciones de derechos: la superación plena del conflicto, mediante el cierre de las heridas sociales y la reparación de la población afectada, al tiempo que se ayuda a los actores a reintegrarse de forma positiva en la sociedad. Es decir, que no solo se busca la terminación a la situación de agresión, sino que además se busca garantizar la no repetición de los hechos, el fortalecimiento del tejido social y del Estado de derecho, y que la paz pactada se convierta en una realidad material duradera.

\section{CONCLUSIONES}

En el 2003 empezaron los acercamientos entre las Autodefensas Unidas de Colombia y el Gobierno del entonces presidente Álvaro Uribe Vélez. Estas aproximaciones llevarían a la emisión de la Ley de Justicia y Paz en el 2005, una norma de carácter transicional que permitiría la desmovilización tanto individual como colectiva de los grupos armados ilegales. Si bien la Ley fue ampliamente criticada, debiendo ser revisada de forma profunda por la Corte Constitucional colombiana, su entrada en vigencia permitió la desmovilización de las AUC.

Sin embargo, a pesar de que la desmovilización de las AUC fue presentada en su momento por el Gobierno como una gran victoria en materia de seguridad nacional, han sido muchas y muy duras las críticas realizadas contra el proceso de desmovilización, tanto desde instancias nacionales como internacionales. La primera de estas fue la creación de una norma de justicia transicional que no tenía por objetivo terminar el conflicto ya que la desmovilización de los paramilitares no representaba la culminación de la actividad armada en el interior de la nación.

Además, se concluye que no se ha cumplió con la garantía de no repetición, ya que muchos de los desmovilizados continuaron delinquiendo o retomaron las armas. De igual forma, no se cumplió con las garantías de verdad, justicia y reparación integral de las víctimas, pues hasta la fecha no existe una verdadera claridad sobre los actos realizados por los grupos paramilitares, sobre su responsabilidad legal, ni se ha reparado de forma integral a las víctimas del conflicto, quienes siguen esperando en muchos casos el pago de los perjuicios y la restitución de sus tierras, al igual que la verdad de lo sucedido con sus familiares. Esto último se evidencia en la posterior necesidad de la emisión de la Ley de Víctimas y Restitución de Tierras del 2011, seis años después de Justicia y Paz, que tiene como finalidad lograr avances reales en dicho campo.

Asimismo, no se ha evaluado y puesto un término de tiempo definitivo, tanto al Estado como a los victimarios para hacer efectivos los derechos de los afectados. No se ha logrado uniformidad a la hora de establecer los elementos probatorios que deben 
aportar las personas que quieran hacerse valer como víctimas dentro del proceso de reparación. Otro de los problemas prácticos a los que se enfrenta el cumplimiento de los objetivos es la sobrecarga del sistema judicial, ya que la avalancha de procesados ha conllevado una clara congestión en los despachos judiciales y de investigación.

De la misma manera, se alega que no existe claridad sobre los crímenes de lesa humanidad cometidos por los grupos paramilitares, respecto de los cuales la legislación internacional en el campo de los derechos humanos y del Derecho Internacional Humanitario refrendada por Colombia, obliga al Estado a poner en marcha su aparato judicial para acelerar dichos procesos, buscar la verdad de lo sucedido y ejercer justicia.

Por lo anterior, muchos críticos y estudiosos del proceso de desmovilización opinan que el Estado colombiano está en una posición de alto riesgo que podría llevar a que organismos judiciales internacionales como la Corte Interamericana de Derechos Humanos o la Corte Penal Internacional intervengan en lo referente a la aplicación de la Ley de Justicia y Paz, condenando a Colombia por el continuo incumplimiento.

Esta doble connotación de la desmovilización de los grupos paramilitares como un hecho positivo, pero igualmente como un proceso inacabado y que no cumplió sus metas, genera una aparente contradicción que debería ser estudiada con mayor profundidad, buscando las causas de la coexistencia en el mismo grupo de individuos de dos criterios que se vislumbran como opuestos.

De otro lado, respecto al objetivo de la desmovilización y reincorporación a la vida civil de los combatientes, si bien es cierto que algunos han logrado reincorporarse con éxito en la sociedad, no lo es así para la gran mayoría, pues existe un número importante de desmovilizados que, ante la incapacidad del Estado de generar un proceso sólido de reinserción y un seguimiento eficaz de este, se han reincorporado y vuelto a la delincuencia a través de diferentes tipos de organizaciones como las denominadas bandas criminales "BACRIM", y otros grupos armados, incluso adhiriéndose nuevamente a rezagos de organizaciones de paramilitares no desmovilizados.

\section{REFERENCIAS}

Aguilera, M. (2006). El ELN: entre las armas y la política En Nuestra guerra sin nombre. Transformaciones del conflicto en Colombia (p. 209-266). Bogotá: Norma.

Centro Internacional para la Justicia Transicional - ICTJ. (2014). ¿Qué es la Justicia Transicional? Recuperado de http://ictj.org/es/que-es-la-justicia-transicional

Centro Nacional de Memoria Histórica. (2010). La Rochela memorias de un crimen contra la justicia. Bogotá: Santillana.

Cobban, H. (2007). Amnesty after atrocity: Healing nations after genocide and war crimes. Boulder, CO: Paradigm Publishers. 
Colectivo de Abogados José Alvear Restrepo. (2006). La reglamentación jurídica de las Leyes 782 de 2002 y 975 de 2005 desconoce abiertamente la Constitución Politica y las normas internacionales sobre derechos humanos. Recuperado de http://www.colectivodeabogados.org/IMG/pdf/Comunicado_conjunto_FIDH_CCAJAR.pdf

Colombia. Congreso de la República. (2002). Ley 782 de 2002. Recuperado de http:// www.secretariasenado.gov.co/senado/basedoc/ley_0782_2002.html.

Colombia. Alcaldía de Bogotá. (2003). Decreto 128 de 2003. Recuperado de http:// www.alcaldiabogota.gov.co/sisjur/normas/Norma1.jsp? $\mathrm{i}=7143$

Colombia. Alcaldía de Bogotá. (2004). Decreto 2767 de 2004. Recuperado de http:// www.alcaldiabogota.gov.co/sisjur/normas/Norma1.jsp?i=14690.

Colombia. Fiscalía General de la Nación. (2005). Ley 975 de 2005. Recuperado de http://www.fiscalia.gov.co:8080/Documentos/Normativa/LEY_975_250705.ht

Comisión Colombiana de Juristas. (2005). Sin paz y sin justicia. Recuperado de http://www.coljuristas.org/documentos/boletines/bol_n6_jyp.pdf

Comisión Interamericana de Derechos Humanos. (1999). Violencia y la violación del derecho internacional de los derechos humanos y el derecho internacional humanitario. Recuperado de http://www.cidh.org/countryrep/Colom99sp/ capitulo-4e.htm

Corte Constitucional de Colombia. Sentencia C-928 de 2005 M.P. Jaime Araujo Rentería.

Corte Constitucional de Colombia. Sentencia C-370 de 2006 M.P. Sala Plena.

Corte Constitucional de Colombia. Sentencia C-575 de 2006 M.P. Álvaro Tafur Galvis.

Corte Constitucional de Colombia. Sentencia C-1199 de 2008 M.P. Nilson Pinilla Pinilla.

Corte Constitucional de Colombia. Sentencia T-496 de 2008 M.P. Jaime Córdoba Triviño.

Department of State US. (2001). Foreign Terrorist Organizations. Recuperado de http://www.state.gov/j/ct/rls/other/des/123085.htm (Consultado el 18 de mayo de 2014).

Forero, J. (2005). New Colombia law grants concessions to paramilitaries. New York Times, 3 de junio de 2005. Recuperado de http://www.nytimes.com/2005/06/23/ international/americas/23colombia.html?_r=1\&

Quinche, M. (2009). Derecho constitucional colombiano de la Carta de 1991 y sus reformas. Bogotá: Universidad del Rosario.

Restrepo, J., Spagat, M., \& Vargas, J. (2004). La dinámica del conflicto colombiano: 1988-2003.

Roman, D. (2011). Lustration and transitional justice. Philadelphia: Pennsylvania University Press. 
Salamanca, M. (2007). Violencia política y modelos dinámicos: Un estudio sobre el caso colombiano. San Sebastián: Editorial Alberdania.

Teitel, R. (2000). Transitional justice. Oxford: Oxford University Press.

Universidad Nacional de Colombia, 2009. 